\title{
Occurrence of Early Pregnancy-Associated Thrombocytopenia in Splenectomized Rabbits
}

\author{
Toshiyuki KOJIMA, Yumie ZENIYA and Kazunaga OHSHIMA') \\ Department of Animal Reproduction, National Institute of Animal Industry, \\ Tsukuba-Norindanchi POBox 5, Ibaraki 305, and "Chugoku National Agricultural \\ Experiment Station, Yoshinaga 60, Kawai, Ohda City, Shimane 694, Japan
}

\begin{abstract}
The occurrence of early pregnancy-associated thrombocytopenia (EPAT) in adult female rabbits was examined in the present study. The rabbits were divided into 5 groups: (i) 5 rabbits were superovulated with follicle stimulating hormone (FSH) and human chorionic gonadotropin (hCG) and mated, but the embryos were not recovered; (ii) 6 rabbits were superovulated and mated, and the embryos were recovered; (iii) 8 rabbits were splenectomized and mated, and the embryos were recovered; (iv) 6 rabbits were splenectomized and injected with hCG; and (v) 3 control rabbits underwent sham operations and they were injected with hCG. In each case, blood ( 2 $\mathrm{ml}$ ) was obtained by venipuncture from the marginal ear vein from the day of hCG injection to the day of embryo collection. A significant change of peripheral platelet concentration (PLT) was characterized either by a decrease or by an increase of $>20 \%$ compared with the value of the initial sampling time. The proportions of rabbits which displayed a significant change in PLT were $80 \%$ $(4 / 5)$ in Group i, 83\% (5/6) in Group ii, 100\% (8/8) in Group iii, 83\% (5/6) in Group iv and 67\% (2/ $3)$ in Group v(P>0.05). In Groups $\mathrm{i}$ and ii, 91\% (10/11) of rabbits showed an increase of PLT. In Group iii, 75\% (6/8) of rabbits showed a decrease of PLT (EPAT). In Groups iv and v, although each rabbit showed a decrease of PLT, the PLT patterns were variable. Effects of group (interaction of treatment/condition $\times$ pregnant status) and pregnant status on PLT were significant $(\mathrm{P}<0.0004$ and $P<0.0003$ respectively). No effect of time after hCG injection on PLT was detected. Significant differences of PLT were observed only between Group i or ii and other groups, when least square mean was compared with a variance of time after hCG injection. From the results of the present study, splenectomy for the pregnant rabbits was requisite for an occurrence of EPAT. Also, the results suggest that EPAT does not occur in normal rabbits. Observations in splenectomized rabbits suggest that platelet activation may be occurring in early pregnancy but not to a sufficient degree to cause measurable thrombocytopenia in peripheral blood.

Key words: Rabbit, Early pregnancy-associated thrombocytopenia, Platelet concentration, Splenectomy, Reservoir of platelets.
\end{abstract}

(J. Reprod. Dev. 42: 95-100, 1996)

E arly pregnancy-associated thrombocytopenia (EPAT) in mice is characterized by a decline in

Accepted for publication: February 9, 1996

Correspondence to: T. Kojima (Present address: National Livestock Breeding Center, Ministry of Agriculture, Forestry and Fisheries, Odakurahara-1, Nishigoh, Nishishirakawa, Fukushima 961, Japan) the peripheral platelet concentration (PLT) and the splenic platelet population [1-3]. It is possibly caused by maternal platelet activation due to the secretion of platelet-activating factor (PAF; $1-0$ alkyl-2-acetyl-sn-glycero-3-phosphocholine) from the embryo [3]. It has recently been shown that localized platelet activation occurs in the uterine 
tube during early pregnancy [4]. EPAT is the first defined physiological response to pregnancy. Other researchers have implied that PAF induces the production of early pregnancy factor (EPF) components in mice [5] and in rabbits [6]. Those results suggested that embryo-derived PAF may be the ovum factor responsible for triggering the generation of serum EPF activity during the preimplantation stages of pregnancy.

Preliminary results in humans $[7,8]$ and in marmoset monkeys [9] have suggested that EPAT is caused by the embryonic product. This maternal physiological alteration may be universal in mammals. The spleen acts as a reservoir of platelets and a splenectomy will cause vascular consumption of platelets resulting in splenic contraction and platelet expulsion [1].The removal of this reservoir means that any change in the total platelet population is reflected as a change in the peripheral blood platelet count. In the present study, occurrence of EPAT was examined in mated rabbits that did or didn't undergo a splenectomy, and compared with unmated rabbits.

\section{Materials and Methods}

\section{Animals}

Adult female Japanese White rabbits (Oryctolagus cuniculus var. domesticus), 1 to 2 years old, and weighing approximately 4 to $5 \mathrm{~kg}$, were used in the present study. These rabbits were purchased from a commercial breeder, Ichikawaya (Chiba, Japan). They were kept in an individual pen located in a temperature and light controlled room (25 C; light/dark: $12 \mathrm{~h} / 12 \mathrm{~h}$ ) for at least 4 weeks before the study started. Adult male bucks for mating were kept in a separate pen in the same room. They were on a concentrated feed ration and they consumed water ad libitum.

\section{Experimental design}

A total of 28 adult female rabbits were initially randomly distributed to 4 treatment groups. The superovulated group was divided into 2 groups according to the result of embryo collection. Consequently, rabbits were re-grouped as follows: (Group i) 5 rabbits were superovulated with follicle stimulating hormone (FSH; Antrin, Denka Pharmaceutical Ltd., Kawasaki, Japan) and human chorionic gonadotropin (hCG; Puberogen, Sankyo
Zoki Co. Ltd., Tokyo, Japan) and were mated, but no embryos were recovered from them; (Group ii) 6 rabbits were superovulated, mated, and recovered embryos; (Group iii) 8 rabbits were splenectomized and mated, and embryos were recovered from them; (Group iv) 6 rabbits were splenectomized and injected with hCG; and (Group v) 3 rabbits underwent sham operations and were injected with hCG (see Table 1).

\section{Splenectomy and sham operation}

Eleven female rabbits were each anesthetized by intravenous injection of $1 \mathrm{ml}$ Pentobarbital sodium (50 mg/ml, Nembutal, Abbott Lab., Chicago, USA) and the spleen was removed through a midventral incision. The major blood vessels were ligated. The spleen was excised. Animals were left to recover for 1 month before any further treatments. For the sham operation, 3 other female rabbits were anesthetized and each rabbit's spleen was exposed to air through a midventral incision and returned to the abdominal cavity without being excised. Some splenectomized rabbits were repeatedly used.

\section{Mating and hCG injection}

In Groups i and ii, each female rabbit was subcutaneously administered with $3 \mathrm{mg}$ of FSH by the 6-split injection method followed by an intravenous injection of $100 \mathrm{IU}$ of hCG $12 \mathrm{~h}$ following the last FSH injection $[10,11]$. Immediately after hCG injection, each female rabbit was placed with two fertile bucks to mate. In Group iii, each splenectomized rabbit was intravenously injected with 100 IU of hCG and mated with two fertile bucks. In Groups iv and v, rabbits were intravenously administered $100 \mathrm{IU}$ of hCG to induce pseudopregnancy. All sampling times were calculated as hours from the time of hCG injection. In all cases mating was done within $10 \mathrm{~min}$ after hCG injection.

\section{Embryo collection}

Each mated rabbit was anesthetized and the oviducts and the uterus were excised through a midventral incision. The oviducts and the uteri were flushed down from the infundibulum with $10 \mathrm{ml}$ of modified Dulbecco's phosphate buffered saline solution [12] containing 10\% heat-inactivated pooled female rabbit serum. Embryos were recovered $60 \mathrm{~h}$ after hCG injection for morula staged embryos or 86 h, 110 h, 134 h, or 158 h for various blastocyst staged embryos respectively. 
Table 1. Occurrence of early pregnancy associated thrombocytopenia (EPAT) in mated/unmated rabbits with various conditions

\begin{tabular}{|c|c|c|c|c|c|c|c|}
\hline Group & Conditions & Treatment & Mating & $\begin{array}{l}\text { Rabbit } \\
\text { No. }\end{array}$ & Resulta & $\begin{array}{l}\text { Major change } \\
\text { in PLTb }\end{array}$ & EPATc \\
\hline \multirow{5}{*}{$\mathrm{i}$} & \multirow{5}{*}{ Superovulated } & \multirow{5}{*}{$\mathrm{FSH}+\mathrm{hCG}$} & \multirow{5}{*}{+} & 9H015 & UFO & $+40(\%)$ & \\
\hline & & & & $8 \mathrm{H} 353$ & NR & +27 & \\
\hline & & & & 9H035 & UFO & +54 & \\
\hline & & & & $8 \mathrm{H} 243$ & UFO & +18 & \\
\hline & & & & 7H537 & NR & +61 & \\
\hline \multirow{6}{*}{ ii } & \multirow{6}{*}{ Superovulated } & \multirow{6}{*}{$\mathrm{FSH}+\mathrm{hCG}$} & \multirow{6}{*}{+} & 9H025 & morula & +30 & \\
\hline & & & & $8 \mathrm{H} 291$ & morula & +158 & \\
\hline & & & & 9H033 & morula & +15 & \multirow{4}{*}{ EPAT } \\
\hline & & & & $8 \mathrm{H} 280$ & morula/UFO & +74 & \\
\hline & & & & $8 \mathrm{H} 227$ & morula & $-21,+24$ & \\
\hline & & & & $8 \mathrm{H} 083$ & morula & +20 & \\
\hline \multirow{8}{*}{ iii } & \multirow{8}{*}{ Splenectomized } & \multirow{8}{*}{ hCG } & \multirow{8}{*}{+} & $8 \mathrm{H} 720$ & ex blasto & -80 & EPAT \\
\hline & & & & 7H725 & blasto & -22 & EPAT \\
\hline & & & & $8 \mathrm{H} 294$ & ex blasto & +119 & \\
\hline & & & & $8 \mathrm{H} 293$ & bla/UFO & $-19,+50$ & \\
\hline & & & & $8 \mathrm{H} 299$ & ex blasto & $-27,+39$ & EPAT \\
\hline & & & & $8 \mathrm{H} 171$ & ex blasto & -83 & EPAT \\
\hline & & & & 7H817 & blasto & -32 & EPAT \\
\hline & & & & $8 \mathrm{H} 289$ & ex blasto & -36 & EPAT \\
\hline \multirow{6}{*}{ iv } & \multirow{6}{*}{ Splenectomized } & \multirow{6}{*}{ hCG } & \multirow{6}{*}{-} & $8 \mathrm{H} 022$ & & $-13,+47$ & \\
\hline & & & & $8 \mathrm{H} 299$ & & +45 & \multirow[b]{5}{*}{ decrease } \\
\hline & & & & $8 \mathrm{H} 703$ & pseudo- & -41 & \\
\hline & & & & $8 \mathrm{H} 022$ & pregnancy & +41 & \\
\hline & & & & $8 \mathrm{H} 289$ & & -18 & \\
\hline & & & & 8H198 & & -34 & \\
\hline \multirow{3}{*}{$\mathrm{v}$} & \multirow{3}{*}{ Sham operated } & \multirow{3}{*}{ hCG } & \multirow{3}{*}{-} & $8 \mathrm{H} 351$ & pseudo- & -35 & \multirow{3}{*}{$\begin{array}{l}\text { stable } \\
\text { decrease }\end{array}$} \\
\hline & & & & $8 \mathrm{H} 353$ & pregnancy & $+36,-40$ & \\
\hline & & & & $8 \mathrm{H} 244$ & & -15 & \\
\hline
\end{tabular}

a UFO (unfertilized ova), NR (nothing recovered), ex (expanded), bla/blasto (blastocyst).

${ }^{b}$ Peripheral platelet concentration (PLT) in $8 \mathrm{H} 703$ and $8 \mathrm{H} 351$ showed a stable pattern except for those values written in the table.

c Significant change of PLT was characterized either by a decrease or by an increase of $>20 \%$ compared to the value of the initial day (pre-mating or pre-hCG injection). In particular, EPAT was determined as a significant decrease in PLT.

The recovered ova were evaluated morphologically with a stereomicroscope (Nikon, Tokyo, Japan) and / or an inverted microscope $(\times 200, \mathrm{CK}$, Olympus, Tokyo, Japan).

\section{Blood sampling}

Blood (approximately $2 \mathrm{ml}$ ) was obtained by venipuncture from the marginal ear vein into a siliconized plastic bottle containing EDTA-2K (Erma, Tokyo, Japan). Blood sampling was conducted from immediately before hCG injection to immediately before anesthetization for surgical embryo collection or to the corresponding day for pseudopregnant rabbits. Sampling frequency was as follows: for Groups i and ii, $14 \mathrm{~h}, 28 \mathrm{~h}, 44 \mathrm{~h}$ and $60 \mathrm{~h}$ after hCG injection, for Groups iii, iv and $\mathrm{v}$, 14 h, 18 h, 22 h, 26 h, 38 h, 42 h, 46 h, 50 h, 62 h, 66 h, $70 \mathrm{~h}, 86 \mathrm{~h}, 110 \mathrm{~h}, 134 \mathrm{~h}$ and $158 \mathrm{~h}$ after hCG injection. Each blood sample was kept at room temperature $(25 \mathrm{C})$ and the enumeration of peripheral platelets was performed within an hour using a semiautomatic blood cell counter (PC-608, Erma, Tokyo, Japan). The PLT value of the blood obtained before hCG injection was designated as 100 for the individual rabbit. Therefore, the PLT value of the subsequent blood sampling time was used 
as a relative value for analysis unless otherwise stated.

\section{Statistical analysis}

The general liner models procedure of the Statistical Analysis System (SAS ${ }^{\circledR}$ ) [13] with the least square means was used to analyze the effects of superovulation, splenectomy, pregnant status and sampling time after hCG injection on PLT during the preimplantation period of rabbit embryos. The model was as follows:

$$
\mathrm{Y}_{\mathrm{ijk}}=\mu+\mathrm{P}_{\mathrm{i}}+\mathrm{S}_{\mathrm{j}}+\mathrm{PT}_{\mathrm{ik}}+\mathrm{e}_{\mathrm{ijk}}
$$

where

$\mu=$ overall mean,

$\mathrm{P}_{\mathrm{i}}=$ effect of pregnancy status,

$S_{j}=$ effect of sampling time after hCG injection,

$\mathrm{PT}_{\mathrm{ik}}=$ interactions between pregnant status and treatment/conditions, and

$\mathrm{e}_{\mathrm{ijk}}=$ residuals.

Other data were analyzed using the $\mathrm{X}^{2}$ test. Significant difference was declared at $\mathrm{P}<0.05$.

\section{Results}

The data of the present study were summarized in Table 1. A significant change of PLT was characterized either by a decrease or by an increase of $>20 \%$ compared with each value of the initial sampling time. The proportions of rabbits indicating significant change in PLT were $80 \%(4 / 5)$ in Group i, 83\% (5/6) in Group ii, 100\% (8/8) in Group iii,

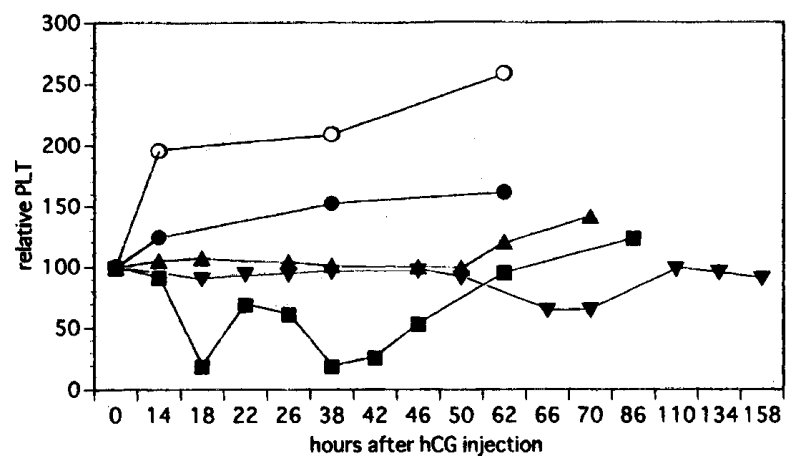

Fig. 1. Representative profiles of relative peripheral platelet concentration from the 5 respective groups. : Group i(7H537); — $\bigcirc$ - Group ii(8H291); : Group iii(8H720); - - - : Group iv(8H022); $-\boldsymbol{\nabla}-$ : Group v(8H351).
$83 \%(5 / 6)$ in Group iv and 67\% (2/3) in Group v $(\mathrm{P}>0.05)$. In Groups i and ii, 91\% (10/11) of rabbits showed an increase in PLT. To the contrary, 6 $(75 \%)$ out of 8 rabbits in Group iii showed a decrease in PLT (EPAT). The PLT patterns were variable in Groups iv and v, although one rabbit in each group (8H198 and 8H353) showed a decrease in PLT. Figure 1 shows the representative profiles of PLT from the 5 respective groups. The representative rabbit (8H720) from Group iii showed one-sided decrease of PLT (EPAT). On the other hand, the representative rabbits from Groups i, ii, iv and v demonstrated no remarkable decrease of PLT, although 8H291 from Group ii showed a remarkable increase of PLT. On the general linear models procedure of SAS, the effects of group (interaction of pregnant status $\times$ treatment / conditions) and pregnant status on PLT were significant $(\mathrm{P}<0.0005)$. No effect of time after hCG injection on PLT was detected $(\mathrm{P}=0.4780)$. Significant differences were observed only between Group i or ii and each other group, when least square mean was compared with a variance of time after hCG injection (Tables 2 and 3). Significant differences in PLT were seen between non- pregnant rabbits and pseudopregnant rabbits $(\mathrm{P}<0.005)$, and between pregnant rabbits and pseudopregnant rabbits $(\mathrm{P}<0.0005)$ (Tables 4 and 5 ).

Table 2. Least square mean and standard error of lsmeans of PLT in each group

\begin{tabular}{crrc}
\hline Group & $\mathrm{n}$ & lsmeans & standard error of lsmeans \\
\hline i & 5 & 123.8 & 7.80 \\
ii & 6 & 135.6 & 7.74 \\
iii & 8 & 102.5 & 3.65 \\
iv & 6 & 102.3 & 3.93 \\
v & 3 & 96.9 & 5.27 \\
\hline
\end{tabular}

Table 3. Significant levels (probabilities) among groups in analysis of general linear models procedures using least square mean

\begin{tabular}{cccccc}
\hline & i & ii & iii & iv & v \\
\hline i &. & 0.2318 & 0.0101 & 0.0115 & 0.0036 \\
ii & &. & 0.0001 & 0.0001 & 0.0001 \\
iii & & &. & 0.9692 & 0.3468 \\
iv & & & & $\cdot$ & 0.3863 \\
v & & & & & $\cdot$ \\
\hline
\end{tabular}


Table 4. Least square mean and standard error of lsmeans of PLT in each pregnant status

\begin{tabular}{lrcc}
\hline Pregnancy status & $\mathrm{n}$ & lsmeans & standard error of lsmeans \\
\hline Non-pregnant & 5 & 123.8 & 7.80 \\
Pregnant & 14 & 119.0 & 4.35 \\
Pseudo-pregnant & 9 & 99.6 & 3.49 \\
\hline
\end{tabular}

\section{Discussion}

O'Neill et al. [14] used a splenectomized mouse bioassay for the detection of PAF. In that study, splenectomized mice were used to increase the sensitivity of the EPAT-bioassay. The mouse spleen acts as a reservoir of platelets and treatments which cause vascular consumption of platelets result in splenic contraction and expulsion of platelets [1]. The removal of this reservoir means that any change in the total platelet population is reflected as a change in the peripheral blood platelet count [2]. In the present study, 6 rabbits showed EPAT in Group iii. Therefore, both conditions of splenectomy and mating which resulted in pregnancy appeared to be requisite for an occurrence of EPAT. No significant difference in the pattern of PLT change was observed between Group i and Group ii. This meant that pregnancy was not a sufficient condition to induce EPAT in maternal peripheral blood circulation in rabbits. However, the cause of the similar pattern in Groups i and ii was obscure. The treatment of superovulation might have had some effect on PLT change.

In a previous study using bilaterally transferred bovine embryos, most of the twin or single pregnant cows exhibited a temporary increase or a temporary decrease in PLT, possibly depending upon the difference in the size of maternal platelet pool, while no such a change in PLT was seen in the control cows (unpublished data). The bidirectional PLT change has also been seen in pregnant women subjected to IVF-ET program [15]. In the present study, pregnant rabbits did not show a
Table 5. Significant levels (probabilities) among pregnancy statuses in analysis of general linear models procedures using least square mean

\begin{tabular}{|c|c|c|c|}
\hline & non-pregnant & pregnant & pseudo-pregnant \\
\hline $\begin{array}{l}\text { non-pregnant } \\
\text { pregnant } \\
\text { pseudo-pregnant }\end{array}$ & . & $\begin{array}{c}0.5530 \\
.\end{array}$ & $\begin{array}{l}0.0037 \\
0.0003\end{array}$ \\
\hline
\end{tabular}

temporary decrease in PLT, while they showed a temporary increase in PLT. Also, the presence of larger quantity of embryos in the reproductive tract did not enhance the intensity of PLT change in the present study. To the contrary, the splenectomized pregnant rabbits exhibited a decrease in PLT. Although the previous studies suggested that rabbit blastocysts did not appear to be able to synthesize PAF [16, 17], a recent study [18] demonstrated that PAF was detected in the culture medium at all stages from 2-cell embryos to blastocysts. Therefore, EPAT is likely to result from the presence of PAF produced by embryos in rabbits. As PAF has been found in the uterine endometrium from rabbits [16], EPAT in rabbits may be due to PAF derived both from the embryos and the uterine endometrium.

In Group iii, the developmental stage of recovered embryos was older than that in Group ii. This difference in the duration of blood sampling did not appear to reflect the pattern of PLT change because EPAT in Group iii was seen $60 \mathrm{~h}$ after mating and hCG injection.

The result suggested that EPAT dose not physiologically occur in normal rabbits, but that EPAT was clearly observed in splenectomized rabbits.

\section{Acknowledgments}

The authors were very grateful to Dr. Chris $\mathrm{O}^{\prime}$ Neill for reviewing this manuscript. The authors also thank the staff of the second animal management section of NIAI for the supply and care of animals.

\section{References}

1. $\mathbf{O}^{\prime}$ Neill C. Thrombocytopenia is an initial maternal response to fertilization in mice. J Reprod Fert 1985; 73: 559-566.
2. $\mathbf{O}^{\prime}$ Neill C. Examination of the causes of early pregnancy-associated thrombocytopenia in mice. J Reprod Fertil 1985; 73: 567-577. 
3. O'Neill C. Partial characterization of the embryoderived platelet-activating factor in mice. J Reprod Fertil 1985; 75: 375-380.

4. Stein BA, O'Neill C. Morphometric evidence of changes in the vasculature of the uterine tube of mice induced by the 2-cell embryo on the second day of pregnancy. J Anat 1994; 185: 397-403.

5. Orozco C, Perkins T, Clarke FM. Platelet-activating factor induces the expression of early pregnancy factor activity in female mice. J Reprod Fertil 1986; 78: 549-555.

6. Sueoka K, Dharmarajan AM, Miyazaki T, Atlas SJ, Wallach EE. Platelet activating factor-induced early pregnancy factor activity from the perfused rabbit ovary and oviduct. Am J Obstet Gynecol 1988; 159: 1580-1584.

7. O'Neill C, Gidley-Baird AA, Pike IL, Porter RN, Sinosich MJ, Saunders DM. Maternal blood platelet physiology and luteal-phase endocrinology as a means of monitoring pre- and postimplantation embryo viability following in vitro fertilization. $J$ in Vitro Fert Embr Trans 1985; 2: 87-93.

8. Roberts TK, Adamson LM, Smart YC, Stanger JD, Murdoch RN. An evaluation of peripheral blood platelet enumeration as a monitor of fertilization and early pregnancy. Fertil Steril 1987; 47: 848-854.

9. Hearn JP, Gidley-Baird AA, Hodges JK, Summers PM, Webley GE. Embryonic signals during the peri-implantation period in primates. J Reprod Fertil (Suppl) 1987; 36: 49-58.

10. Kojima T, Soma T, Oguri N. Effect of rapid addition and dilution of dimethyl sulfoxide on the viability of frozen-thawed rabbit morulae. Cryobiology 1985; 22: 409-416.
11. Kojima T, Soma T, Oguri N. Effect of rapid addition and dilution of dimethyl sulfoxide and 37C equilibration on viability of rabbit morulae thawed rapidly. Cryobiology 1987; 24: 247-255.

12. Whittingham DG. General aspects of egg culture and preservation. In: Rowson LEA (ed.), Egg Transfer in Cattle. Luxembourg: Comm. Eur. Commun; 1976: 101-116.

13. Statistical Analysis System. SAS ${ }^{\circledR}$ User's Guide: Statistics, Version 6.03 Ed, Cary, NC: SAS Inst., Inc.; 1988.

14. O'Neill C, Gidley-Baird AA, Pike IL, Saunders DM. Use of a bioassay for embryo-derived platelet-activating factor as a means of assessing quality and pregnancy potential of human embryos. Fertil Steril 1987; 47: 969-975.

15. O'Neill C, Collier M, Saunders DM. Embryo-derived platelet-activating factor: its diagnostic and therapeutic future. NY Acad Sci 1988; 541: 398-406.

16. Angle MJ, Jones MA, McManus LM, Pinckard RN, Harper MJK. Platelet-activating factor in the rabbit uterus during early pregnancy. I Reprod Fertil 1988; 83: 711-722.

17. Kasamo M, Brandt M, Ishikawa M, Shimizu T, Harper MJK. In-vitro prostaglandin release and platelet-activating factor accumulation in isolated endometrial cells from pregnant and pseudopregnant rabbits. Biol Reprod 1992; 46: 829-845.

18. Minhas BS, Zhu YP, Kim HN, Burwinkel TH, Ripps BA, Buster JE. Embryonic platelet activating factor production in the rabbit increases during the preimplantation phase. J Assit Reprod Gen 1993; 10: 366-370. 